\title{
CONHECIMENTO, COMPREENSÃO E COMPETÊNCIA NOS ESTUDOS DA LINGUA(GEM)
}

\begin{abstract}
Elaine Ferreira do Vale Borges é formada em Letras pela Unesp, mestre em Linguística Aplicada pela Unicamp e doutora em Educação pela USP. Fez estágio doutoral na Universidade de Murcia (Espanha) e residência pós-doutoral na UFMG, onde desenvolveu e lecionou disciplina no curso de Letras. Atualmente faz pesquisa na perspectiva da complexidade no contexto de ensino e aprendizagem de língua materna e línguas estrangeiras.

E-mail: elainefvb@uol.com.br
\end{abstract}

Resumo

Neste artigo, apresento uma reflexão sobre o uso dos termos conhecimento, compreensão $\mathrm{e}$ competência nos estudos da lingua(gem). A discussão centraliza-se nas posições de Chomsky e Hymes, culminando na visão contemporânea de competência ecológica.

\begin{abstract}
In this paper I present a reflection on the use of the terms knowlegde, compreension and competence in the language studies. The discussion focuses on the positions of Chomsky and Hymes, culminating in the contemporary vision of ecological competence.
\end{abstract}

\section{Introdução}

No panorama dos estudos da lingua(gem), as obras de Chomsky (1965) e depois de Hymes (1972) trazem para o contexto de reflexões o termo competência. Chomsky propõe a dicotomia competência (gramática) e desempenho (uso) na compreensão do desenvolvimento da língua materna (LM) e enfatiza uma concepção particular do termo conhecimento (tácito, intrínseco) e, posteriormente, da noção de competência pragmática (habilidade para o uso) (Chomsky, 1980). Hymes, por sua vez, amplia o sentido do termo competência chomskyano e cunha a noção de competência comunicativa (uso linguístico) que é diretamente assimilada nas investigações e estudos sobre o ensino/aprendizagem e aquisição de línguas estrangeiras (LEs) e/ou segunda língua (L2). Termo ressignificado posteriormente por vários linguísticas aplicados como, por exemplo, Canale \& Swain (1980), Bachman (1990), Celce-Murcia, Dörnyei \& Thurrel (1995) e Celce-Murcia (2007). Antes, porém, Saussure (1916/1972) já havia proposto a distinção entre língua (langue) e fala (parole) e Palmer (1917/1968) a noção de compreensão subconsciente (competência gramatical). Desde então, todos esses termos protagonizam um papel importante no desencadeamento e na evolução das discussões sobre o ensino de línguas e a aquisição de LE/L2 e LM, mas não sem fortes antagonismos, como este artigo visa mostrar em seu desenvolvimento. Atualmente, a discussão tende a privilegiar a junção das diferentes contribuições sobre os termos destacados no que se pode compreender por competência ecológica, principalmente enfatizada no paradigma da complexidade.

Dentro do panorama apresentado acima, neste artigo, viso apresentar a evolução na discussão (e controvérsias subjacentes) sobre o uso dos termos conhecimento (tópico 1), compreensão (tópico 2) e competência (tópicos 3, 4 e 5) e seus significados nos 
estudos da lingua(gem), fundamentada principalmente nas visões de Chomsky (1965 e 1980) e Hymes (1972) - precursores historicamente reconhecidos no tema das competências na aquisição de LM e LE/L2 -, mas trazendo as contribuições de outros autores igualmente importantes como Piaget, Palmer, Halliday e tantos outros inseridos em contextos mais específicos de estudos sobre LE/L2. Ao final, no tópico 6, desenvolvo uma pequena reflexão sobre o termo competência ecológica, em van Lier (2000) e Kramsch (2006), no cenário do paradigma da complexidade: promessa de novos encaminhamentos nas reflexões e discussões do tema em questão.

\section{1) Conhecimento}

Em 1970, o debate clássico entre Piaget e Chomsky perpetuado no livro organizado e compilado por Piattelli-Palmarini ([1978] 1983) traz à tona, para as discussões sobre a compreensão do desenvolvimento/aquisição da linguagem, uma reflexão importante sobre os termos conhecimento e competência e/ou tipos de conhecimento.

Em Piaget ([1978] 1983), o termo conhecimento é empregado com um sentido forte de significação e/ou assimilação do mundo que se promove na interação entre as ações (esquemas motores) de uma pessoa sobre as solicitações do meio; ou seja, é um processo construtivo-evolutivo constatado nas exigências da experiência (através da adaptação entre a assimilação e a acomodação), porém iniciado nos processos cognitivos e/ou na estruturação mental interna do organismo humano - já que o organismo teria uma predisposição (não programada geneticamente) para o ato de conhecer.

Para Chomsky ([1978] 1983), existe um tipo de conhecimento (de compreensão geral e/ou do senso comum) que sugere a noção de habilidade e outro tipo (mais específico) que subentende um saber tácito intrínseco. O termo competência em sua obra subentende a noção de conhecimento como um saber tácito intrínseco. Noção que se aproxima da de Piaget no que, em ambos os autores, a concepção do termo conhecimento se afasta do sentido de senso comum, mas com a diferença entre a visão de "inato" (Chomsky) e "construído" (Piaget), que serão explicadas mais a frente no desenvolvimento deste tópico. Dessa forma, Chomsky (1980, p. 50) explica que no desenvolvimento de seus estudos, "o termo 'competência' entrou na literatura técnica em um esforço de evitar complicações com o vai e vem de problemas relacionados ao "conhecimento""; porém, esse termo, no que se refere aos seus trabalhos, "é enganoso no que ele sugere como "habilidade'. Isso equivale a dizer que o termo competência, em Chomsky, não tem nada a ver com a noção do senso comum de ser hábil, de se ter capacidade para fazer algo, mas sim com a noção de uma aptidão inata para o desenvolvimento/aquisição da língua com a qual se tem contato na infância.

A inteligência - como descrita na epistemologia genética de Piaget - tem um 
aspecto hereditário (predisposição genética), porém só se desenvolve "mediante uma organização de ações sucessivas, exercidas sobre objetos" e na "elaboração contínua de operações e de novas estruturas" (Piaget, [1978] 1983, p. 39). Assim, o conhecimento não resulta da simples observação, como supunham os behavioristas e/ou empiristas, nem de estruturas cognitivas (núcleo fixo) a priori ou inatas, como propôs Chomsky e os racionalistas em geral.

Já para Chomsky, o fator hereditário ou herança biológica se configura na existência de um núcleo fixo, ou seja, "uma capacidade de linguagem geneticamente determinada" que "especifica uma certa classe de 'gramáticas humanamente acessíveis'" (competência intrínseca) (Chomsky, [1978] 1983, p. 50) e que se manifesta nas crianças no contato (desenvolvimento de sistemas de desempenho, como estratégias de produção e percepção) com uma determinada comunidade linguística, produzindo assim a língua específica daquela comunidade (a sua LM).

Segundo Piaget ([1978] 1983), o núcleo fixo de Chomsky seria em verdade não inato, mas construído durante o desenvolvimento da inteligência sensório-motora da criança, que se manifesta a partir do nascimento e vai até os dois anos de idade.

Nesse contexto, como destaca Piattelli-Palmarini ([1978] 1983, p. 71), Piaget e Chomsky divergem na maneira de "explicar tanto a necessidade (lógica e factual) quanto a "natureza' do "núcleo fixo'" (processos cognitivos internos); embora ambos admitam a sua existência - tema ainda em plena discussão e evolução ${ }^{i}$ em diversas áreas que estudam a aquisição e desenvolvimento da linguagem humana.

Tudo isso acaba influenciando também na diferença conceitual do termo conhecimento. $\mathrm{O}$ que equivale a dizer que podemos pensar em três tipos de conhecimento nos estudos da linguagem, a saber:

- conhecimento (piagetiano) como significação/construção, o cognoscere (conhecer pelos sentidos através da interação sujeito-meio);

- conhecimento (senso comum) como habilidade, o habilitatis, ou conjunto dos domínios onde se exerce a aprendizagem.

- conhecimento (chomskyano) tácito intrínseco ou competência.

\section{2) Compreensão subconsciente}

O foneticista e linguista inglês Harold E. Palmer (1877-1949) - justamente com Albert S. Hornby (1898-1978) - preocupou-se fundamentalmente com o estudo científico dos métodos de ensino de línguas, envolvendo-se para isso com o denominado método direto (de Maximiliam D. Berlitz, 1852-1921) e com as novas ideias do movimento da reforma (preconizado por Henry Sweet, 1845-1912). Palmer desenvolveu os fundamentos do que ficou conhecido como método oral ou ensino de 
língua situacional ${ }^{\mathrm{ii}}$, de base estrutural e behaviorista. No entanto, as reflexões de Palmer foram além das expectativas do pensamento da época.

Em sua obra de 1917, The Scientific Study and Teaching of Language (Palmer, 1917/1968), o linguista enfatiza a noção de compreensão subconsciente ou período de incubação, que "subentende uma forma de interação [professor-aluno] sem qualquer pressão para a reciprocidade, ou seja, se os aprendizes querem participar eles podem, mas não há necessidade" (Howatt \& Widdowson, 2004, p. 273). Isso devido ao fato de que Palmer acreditava que a criança só começava a falar sua LM depois desse período de incubação, "durante o qual ela teria recebido passivamente e estocado em sua mente uma considerável quantidade de material linguístico - sendo que o mesmo processo poderia proveitosamente ser empregado por pessoas mais adultas no estudo de línguas estrangeiras" (Lemieux, 1964, p. 323).

Mas, o reconhecimento da importância desse processo cognitivo passivo não fez com que Palmer deixasse de enfatizar também o trabalho ativo dos aprendizes. Trabalho que não deveria ser confundido com a fala dos alunos que gostam de se expressar mesmo sem ter tido necessariamente a melhor compreensão.

Para Palmer, esse conceito interno/cognitivo de ensino/aprendizagem correspondia à lei natural do próprio processo de aquisição da linguagem - já que "aprendemos sem saber o que estamos aprendendo" e "formamos sentenças em obediência inconsciente a algumas regras desconhecidas por nós" (Palmer, 1921/1964, p. 44 e 5). E é por esse motivo que o método oral tem como base metodológica proporcionar "formas de trabalho [divididas em diferentes estágios: elementar, intermediário, avançado] em que as forças de assimilação inconsciente dos pupilos são treinadas e desenvolvidas" (Palmer, 1922, p. 11) em função de capacitá-los para a leitura, a escrita e a conversação na língua-alvo. Mas essas formas de trabalho (compreensão subconsciente, drills, articulação e fluência, fonética e semântica, leitura mental e oral, composição, tradução, estudo de textos, etc.) devem ser planejadas de uma maneira em que, ao serem desenvolvidas em sala de aula, "a atenção do aluno deva ser direcionada para o tema e não para a forma em que esse tema é expressado" - já que o "foco de atenção [na gramática da língua] milita contra o próprio funcionamento da capacidade natural de assimilação" (Palmer, [1921] 1964: 51 e 8).

De acordo com Howatt \& Widdowson (2004), as reflexões de Palmer, no que se refere à compreensão da gramática da LM e ao seu processo de aquisição/assimilação natural pela criança, podem ser consideradas como um resumo das próprias ideias da teoria gerativo-transformacional de Chomsky formulada quase cinquenta anos depois; o que pode-se levar a relacionar a compatibilidade entre as noções de compreensão subconsciente de Palmer e de conhecimento tácito intrínseco (competência) de Chomsky.

\section{3) Competência linguística e pragmática}


As ideias revolucionárias de Noam Chomsky trazem para as reflexões sobre a aquisição da linguagem humana uma "precisa descrição matemática" (com fundamentos biológicos e/ou próprios da natureza humana) de traços universais da linguagem associada à "capacidade que têm as crianças de derivar regularidades estruturais [regras de gramática] de sua língua materna; proporcionando-as a construir expressões orais nunca antes ouvidas" (Lyons, 1973, p. 13).

Os primeiros "rascunhos" da distinção entre competência e desempenho - que torna a teoria de Chomsky tão polêmica na área dos estudos da linguagem - aparecem, de acordo com Lyons (1973, p. 38), em sua obra de 1957, Syntactic structures, quando ele distingue "as sentenças geradas pela gramática (a língua) dos enunciados produzidos, em condições normais de uso, pelos que falam uma língua-mãe (o corpus)". A partir dessa obra, Chomsky, ainda segundo Lyons, passa de uma visão empirista para uma racionalista, o que faz com que o linguista mude também a terminologia empregada. Porém, é na obra de 1965, Aspects of the theory of syntax, que Chomsky (1965, p. 3-4; ênfase do autor) verbaliza enfaticamente que faz em sua teoria "uma fundamental distinção entre competência (o conhecimento da língua do falanteouvinte) e desempenho (o uso atual da língua em situações concretas)". Para tanto, o linguista ainda explica que

A teoria linguística é primariamente preocupada com um falante-ouvinte ideal, numa comunidade falante completamente homogênea que conhece sua língua perfeitamente e não é afetada por condições gramaticalmente irrelevantes, tais como limitações de memória, distrações, desvios de atenção e interesse, e erros (aleatórios ou característicos), ao aplicar seu conhecimento da língua em desempenho real (Chomsky, 1965, p. 4).

Em estudos mais recentes (como em Rules and representation), Chomsky reforça que a sua noção do termo competência não está associada à visão de habilidade, mas sim se refere a um conhecimento tácito intrínseco - como já foi enfatizado no tópico 1 deste artigo. Todavia, especificamente em relação à noção de habilidade, Chomsky reformula algumas questões que envolvem o termo desempenho, relacionando-os e acrescentando e/ou reconhecendo uma outra concepção em sua teoria, que ele classificou de competência pragmática. Dessa forma, o autor (1980, p. 224; ênfase do autor) pontua que

Por propósitos de questionamento e exposição, nós podemos proceder no sentido de distinguir competência gramatical de competência pragmática, restringindo a primeira ao conhecimento da forma e significado, e a segunda ao conhecimento de condições e maneiras de uso apropriado, em conformidade com fins variados. Assim, podemos pensar a língua como um instrumento que pode ser posto em uso. A gramática da língua caracteriza o instrumento, determinando propriedades físicas e semânticas intrínsecas de cada sentença. A gramática, então, expressa competência gramatical. Um sistema de regras e princípios constituindo competência pragmática determina como a ferramenta pode efetivamente ser posta em uso. 
De posse desse novo panorama, pode-se concluir as seguintes concepções em Chomsky (1980):

- competência gramatical (linguística): conhecimento tácito intrínseco; conhecimento da língua/gramática (a ferramenta) e seu significado.

- desempenho: o uso atual da língua em situações concretas.

- competência pragmática: conhecimento de condições e maneiras de uso apropriado (da ferramenta), em conformidade com fins variados; habilidade para o uso adequado da língua.

Na mesma obra de 1980, conforme Matthews (1990, p. 71), Chomsky passa a enfatizar a mente como uma "estrutura modular", ou seja, "um sistema composto de subsistemas distintos embora interativos, cada qual tendo suas próprias propriedades e organizados por diferentes princípios". O que equivale dizer que a nossa aptidão linguística (competência gramatical), como um dos subsistemas da mente, porém inato, interage com outros subsistemas (como a competência pragmática, por exemplo) para a produção (desempenho) da linguagem em uso.

De forma bem simplificada, a teoria modular ou a teoria do core grammar (ou core language), segundo Matthews (1990), representa os princípios universais ou inatos de todas as línguas que uma criança possui e que se manifestam no contado com as regras de uso particular de cada língua (peripheral grammar). Ou seja, cada princípio universal em suas finitas variações permite o desenvolvimento de uma determinada língua - sendo o contato com essa língua particular o insumo necessário para acionar o core grammar - ao constituir um conjunto de parâmetros com um conjunto de valores selecionado pela criança durante a sua experiência com a língua materna.

\section{4) Competência comunicativa}

Segundo Criper \& Widdowson (1975, p. 155),

Para saber a língua enquanto um sistema formal, precisamos saber as regras que geram sentenças bem formadas, mas para saber a língua enquanto um significado de interação social, precisamos daquelas convenções de uso que controlam a seleção de sentenças bem formadas, apropriadas para uma situação social particular.

E é exatamente em função da preocupação com as convenções socioculturais da linguagem em uso que o antropólogo e sociolinguista norte-americano Dell Hymes retoma o termo competência em Chomsky e o amplia para sustentar a concepção de competência comunicativa defendida por ele. Para Hymes (1971, p. 4-5), a visão de falante-ouvinte ideal inserido no ponto de vista da linguística teórica chomskyana é 
necessária, mas só se mantém forte dentro de seu próprio mundo, pois "para lidar com as realidades das crianças como seres comunicativos é necessário uma teoria dentro do qual fatores socioculturais tenham um papel explícito e constitutivo". Afinal, de acordo com Hymes, uma criança normal "adquire o conhecimento de sentenças não apenas como gramaticais, mas também como apropriadas".

No artigo de 1972, On communicative competence, Hymes (1972; ênfases do autor) esclarece que competência deve ser compreendida como um termo mais geral (do que havia descrito Chomsky), relacionado às capacidades de uma pessoa, sendo que

A competência é dependente tanto do conhecimento (tácito) quanto do (habilidade para) uso. O conhecimento é distinto, então, tanto da competência (enquanto sua parte) quanto da possibilidade sistêmica (em que sua relação é uma questão empírica).

A 'competência' subjacente ao comportamento de uma pessoa é identificada como um tipo de 'desempenho' [...].

A especificação de habilidade para o uso como parte da competência permite o papel de fatores não cognitivos, como a motivação, como em parte determinando a competência (Hymes, 1972, p. 282-3)

Inserido nos estudos sobre etnografia da fala (ou etnografia da comunicação, termo usado mais recentemente) - que investiga as relações e/ou influências dos valores e aspectos socioculturais no uso da linguagem - Hymes compreende a competência comunicativa como um ponto de interação importante entre o uso da linguagem e a vida social, já que é através dessa competência que um falante demonstra suas habilidades diante de uma determinada situação comunicativa que, por sua vez, é fruto de um ambiente socialmente construído. Assim, é importante considerar a seguinte noção acerca do termo competência em Hymes (1972):

- competência comunicativa: engloba o conhecimento tácito (i.e. competência linguística e fatores cognitivos relacionados) e a habilidade para o uso desse conhecimento (i.e. desempenho e fatores não cognitivos relacionados, como a motivação).

Hymes, preocupado com o papel do comportamento humano na produção da fala, desenvolve, ainda, as noções de comunidade de fala, que subentende ser "um grupo no qual uma particular descrição etnográfica se aplica", sendo que o comportamento comunicativo específico de um dado grupo (ou de uma dada comunidade de fala) é diagnosticado pela análise de seus componentes interativos: ato de fala (a menor unidade, porém considerado como tal dentro de um contexto social, gramatical ou pela entonação), evento de fala (composto por um ou mais atos de fala) e situação de fala (ou seja, situações associadas à fala ou à falta dela e sujeito às regras da fala) (Fasold, 1990, p. 41-2).

\section{5) Competência linguística versus competência comunicativa}

\footnotetext{
Rua Marquês de São Vicente, 225 Gávea/RJ CEP 22453-900 Brasil Ano 2011. Número 13. ISSN 1679-6888. escrita@puc-rio.br
} 
As reflexões em torno do termo competência no campo dos estudos da linguagem vão além das enfatizadas por Chomsky e Hymes; já que muitos estudiosos retomaram as noções de competência linguística, pragmática e comunicativa desses pensadores para uma análise crítica, como exposta a seguir.

Nos trabalhos de Campbell \& Wales (1972) e Greene (1972), a teoria de Chomsky é apresentada como tendo um sentido mais forte (primeiro) e outro mais fracolneutro (segundo) em relação aos termos competência e desempenho. No sentido fraco, a competência se refere ao conhecimento de gramática e o desempenho ao uso desse conhecimento; no sentido forte, a competência se refere ao sistema da gramática e o desempenho aos fatores psicológicos envolvidos na percepção e produção da fala. Campbell \& Wales (1972, p. 257; ênfases dos autores) ainda citam um terceiro sentido para o termo competência em Chomsky, situando-o como um tipo de competência mais restrita que omite a mais importante habilidade linguística, qual seja, "a habilidade de produzir ou compreender enunciados que não são muito gramaticais, mas, mais importante, apropriados ao contexto em que foram produzidos". Nesse sentido, a noção do segundo sentido (mais forte) para o termo competência entra em contraste com esse terceiro, já que os autores relacionam a noção forte do termo com a natureza das habilidades humanas que são específicas da língua. Apesar de os dois sentidos (forte e fraco) estarem relacionados à teoria de Chomsky, de acordo com Campbell \& Wales (1972) e Greene (1972), parece-me que o sentido que mais se aproxima da visão chomskyana de competência (gramatical) e desempenho é o primeiro sentido (mais forte); enquanto que o segundo (mais fraco) e o terceiro sentidos se aproximam mais da concepção de competência comunicativa hymesiana.

Paulston (1974, p. 347-8) destaca uma reflexão sobre possíveis interpretações da noção de competência comunicativa dentro do contexto de ensino de línguas. Para a autora, é típico da área da sociolinguística - da qual ela faz parte - haver uma compreensão do conceito de competência comunicativa, nos moldes propostos por Hymes, como as regras sociais de uso da linguagem; já no campo da psicolingüística, a interpretação do conceito passa a ser de interação linguística na língua-alvo - sendo que esses dois conceitos têm implicações diferentes para o ensino de línguas. Para Paulston (1974), a crescente preocupação com o uso de atividades comunicativas no ensino de língua sempre subentendeu (e subentende) uma ênfase na compreensão do significado. No entanto, a questão que fica é a de "que tipo de significado" está se falando. A autora coloca que a psicolinguista Wilga Rivers, por exemplo, usa a competência comunicativa como um sinônimo para 'expressão espontânea'.

O linguista sociofuncional Halliday (1978), por sua vez, entende a linguagem como algo que contém um significado ideacional ou referencial, que contrapõe à visão de sociolinguistas e antropólogos de linguagem como possuindo um significado social. Ainda de acordo com Paulston (1974), a visão da psicolinguística tende a compartilhar, em alguma medida, a visão chomskyana sobre competência, assim como, em oposição, 
a sociolinguística tende a compartilhar a visão hymesiana sobre a noção de competência. No entanto, esses dois campos de investigação, apesar dos interesses particulares, devem ser mais reconciliadores do que diretamente opostos. Embora a autora enfatize a importância da visão mais pontualmente social de Hymes para o contexto de ensino de línguas.

Halliday (1978), todavia, rejeita a dicotomia competência-desempenho em Chomsky por considerá-la desnecessária para o contexto sociológico, diferenciando-a, em alguma medida, da concepção de competência comunicativa de Hymes (deslocandose da visão fraca em Campbell \& Wales (1972) e Greene (1972) e, sendo assim, se aproximando mais da visão forte desses mesmos autores) - já que Hymes parte da dicotomia chomskyana para sustentar seus argumentos. Halliday (1978) preocupou-se em investigar as possibilidades de comportamento (alcance das ações) e de significados (escolhas semânticas) produzidos (escolhas linguísticas) por um falante no uso da linguagem em determinados contextos sociais, e não enfatizou questões do conhecimento tácito, mas sim do significado potencial produzido por um falante. As possibilidades (termo usado por mim e não pelo autor) em Halliday não possuem a carga da noção de competência (conhecimento tácito intrínseco) chomskyana, e por esse motivo diverge da noção de competência comunicativa hymesiana, apenas na menção que esse autor faz a esse tipo de conhecimento. Nesse contexto, a visão hallidayana nos parece estar mais em acordo com a noção de competência pragmática proposta por Chomsky em sua obra de 1980, Rules and representation.

De acordo com Allen \& Widdowson (1975), o fato de as preocupações de Halliday estarem mais relacionadas à maneira como a estrutura da língua é usada na comunicação e/ou como as funções da linguagem requerem uma certa estrutura linguística e não outra, a visão dele de competência comunicativa é mesmo diferente daquela inserida nos estudos de cunho etnográfico de Hymes. Para os autores, a visão de Halliday está mais relacionada a um "funcionalismo comunicativo" (p. 88), já que a competência comunicativa de Hymes, como já enfatizado, tem a ver com uma "habilidade linguística de produzir ou compreender enunciados que não são muito gramaticais, mas sim apropriados para o contexto em que eles são produzidos" (Campbell \& Wales, 1972, p. 257).

Munby (1978), seguindo o raciocínio das interpretações de Campbell \& Wales (1972) e Greene (1972), prefere usar como fundamentação para a produção de conteúdos de um programa de ensino de línguas para fins específicos (inseridos em um planejamento comunicativo) a noção de competência comunicativa de Hymes, ao invés da de significado potencial de Halliday, embora, segundo Canale \& Swain (1980, p. 21), Munby tenha "adotado a posição teórica sugerida por Halliday da visão da linguagem como opções semânticas derivadas de estruturas sociais". Munby (1978, p. 9) acredita que a noção de competência em Chomsky é válida para as reflexões de ensino de línguas, porém "deve ser ampliada para incluir apropriação contextual" - como fez Hymes. 
Ainda segundo Canale \& Swain (1980, p. 20), Munby estrutura um "modelo de competência comunicativa" que subentende três grandes componentes, a saber: uma "orientação sociocultural" (baseada nos trabalho de Hymes), uma "visão sociosemântica do conhecimento linguístico" (que segue a linha desenvolvida por Halliday sobre a natureza da linguagem), e "regras de discurso" (área aprofundada nos estudos de Widdowson).

Para Canale \& Swain (1980, p. 3), Chomsky

[...] introduziu os termos 'competência' e 'desempenho' na linguística moderna por meio da afirmação da necessidade metodológica de se estudar a língua através de abstrações idealizadas, porém ignorando o que parecia ser um detalhe irrelevante, o comportamento da língua.

Ainda na concepção dos autores, Hymes considera que o termo competência deve ir além do conhecimento de regras da gramática, como fora proposto por Chomsky, contemplando igualmente os conhecimentos das regras de uso da língua. Isso explicaria o uso do termo competência comunicativa, que pretende abarcar tanto um conhecimento tácito (a competência chomskyana), da gramática, quanto um conhecimento que subentende a habilidade de se produzir a língua em contexto de uso, como já enfatizado. Tal habilidade é diferente da noção de desempenho (comunicativo), que se refere aos fatores psicolinguísticos gerais manifestados em situações concretas de uso da linguagem, tais como a volição e a motivação, embora também estejam relacionados a uma noção de habilidade. Lembrando que, para Hymes, os tipos de conhecimento destacados (tácito e habilidade de uso) compõem o termo competência (comunicativa); para Chomsky, é apenas o primeiro (conhecimento tácito) que é considerado como fazendo parte da competência (gramatical). Em seus estudos, Canale \& Swain mantêm-se na linha de raciocínio hymesiana, porém renomeiam o que esse autor classificou de conhecimento das regras de uso para competência contextual ou sociolinguística (regras de uso sociocultural e do discurso).

Canale \& Swain (1980) ainda pontuam que a visão subjacente ao termo competência comunicativa difere entre alguns estudiosos da linguagem. Widdowson, Munby e Halliday, por exemplo, partilham diferentes concepções e/ou alcance conceitual sobre esse mesmo termo. Para Canale \& Swain, Munby compartilha da visão proposta por Hymes em que tanto o conhecimento das regras da gramática (competência gramatical), quanto o conhecimento das regras de uso da linguagem (habilidade) compõem a competência comunicativa. Já Widdowson faz uma separação entre os termos competência comunicativa (referência exclusiva ao conhecimento ou à capacidade relacionados os usos da língua) e competência gramatical (referindo-se às regras da gramática). Halliday, por outro lado, não separa o termo desempenho (comunicativo) da noção de competência comunicativa, como o faz Hymes e a grande maioria (mesmo que implicitamente) das linguísticas aplicadas. Segundo Canale \& Swain, os pesquisadores que seguem essa última linha parecem compartilhar da visão 
de linguistas que trabalham dentro do paradigma chomskyano, ou seja, dentro da versão forte dos termos competência e desempenho, como foi proposta por Campbell \& Wales (1972) e Greene (1972). Hymes, por sua vez, teria rejeitado essa "versão forte".

Na visão de Taylor (1988), há muitos problemas nas interpretações da noção do termo competência em Chomsky na literatura da área, principalmente dentro dos estudos de ensino de línguas. Isso devido a uma falta de distinção clara entre as concepções de estado (conhecimento) e processo (habilidade) que internalizam o conceito do termo dentro da teoria chomskyana. Segundo o autor, Chomsky usou o termo de forma absoluta em que concebe um tipo de conhecimento tácito, que não sugere em hipótese alguma a associação da noção de habilidade - como desenvolvido no tópico 1 deste artigo. No entanto, a interpretação que se faz do termo em Chomsky é de uma forma relativa, ou seja, incorporando a noção de habilidade. Nesse sentido relativo, competência se confunde com habilidade, que se confunde com proficiência.

Ainda segundo Taylor, é para evitar esse tipo de confusão que Chomsky optou pelo uso do termo competência ao invés do termo conhecimento. No entanto, ao usar o termo competência comunicativa de cunho hymesiano, pretende-se estender o termo competência em Chomsky de forma que ele contemple a noção de proficiência e, consequentemente, de habilidade.

Em termos educacionais e/ou pedagógicos, a interpretação correta das bases conceituais do termo competência chomskyano, desenvolvida em uma determinada área, como a Linguística ou a Linguística Aplicada, para o seu uso em determinado contexto de estudo (aquisição de LM ou L2/LE) e de aplicação, faz-se necessária, tendo em vista que tradicionalmente a definição de dicionário (senso comum) do termo competência sugere muito pouco a noção de estado mental ou mesmo de conhecimento tácito como fora usado por Chomsky.

Tão complicada é essa situação da dimensão da interpretação conceitual do termo competência, no que diz respeito às bases que guiam os estudos desenvolvidos nos estudos da lingua(gem), que Taylor revela que nos trabalhos de Wiemann \& Backlund (1980), faz-se uma distinção da noção do termo competência comunicativa sob duas perspectivas: uma cognitiva (competência como um fenômeno mental, no sentido usado por Chomsky); e outra comportamental (competência como comportamento comunicativo real, no sentido encontrado em Hymes).

Já nos estudos desenvolvidos por Halliday (1978), segundo Taylor (1988), o nível psicológico ou cognitivo é rejeitado por ser considerado como desnecessário para as discussões sobre a competência na aquisição de línguas - questão já discutida neste artigo. Isso se dá porque Halliday entende que os estudos da área devam ser realizados de uma perspectiva "interorganismo" - o que ao mesmo tempo o aproximaria e o distanciaria de Hymes, na medida em que o próprio Halliday, ainda de acordo com Taylor (1988, p. 159), notifica que Hymes tentou introduzir "uma dimensão social dentro do que é um conceito essencialmente individual". Na visão de Halliday, Hymes partiria de uma perspectiva - pouco provável de se concretizar - de estudos 
"intraorganismo" ou "psicosociolinguistas". Essa questão da rejeição do mental em favor do comportamental, em minha compreensão, remete-nos à visão essencialmente sustentada pelo behaviorismo radical de Skinner - o que pode reforçar, também, as preocupações destacadas aqui por Taylor.

Ainda de acordo com Taylor (1988), a noção de competência pragmática, destacada por Chomsky, está diretamente ligada à noção de habilidade (competência) para o uso, que Hymes (1972) desenvolveu no artigo em que este autor questiona as ideias de Chomsky. Para Taylor há uma clara correspondência entre as duas noções, o que pode mostrar tanto que Chomsky reconhece as críticas imputadas a ele, quanto um mérito positivo em relação às contribuições de Hymes no que se refere ao termo desempenho.

Nesse contexto, Hymes (1972, p. 279) teria dado um forte destaque à aquisição dessa habilidade (competência) para o uso ao equipará-la em grau de importância à aquisição de competência para a gramática chomskyana, enfatizando que "dentro de uma matriz desenvolvimental, em que o conhecimento das sentenças de uma língua é adquirido, as crianças também adquirem o conhecimento de um conjunto de maneiras em que as sentenças são usadas".

No entanto, a noção de habilidade, aqui subjacente, acaba se alocando também no termo competência comunicativa (que subentende conjuntamente um conhecimento das regras da gramática, a própria competência gramatical chomskyana, e um conhecimento das regras de uso) - já que Hymes o separou do termo desempenho. Nesse aspecto, segundo Taylor, Hymes teria visivelmente se equivocado na interpretação do termo competência em Chomsky e "transferido" seu equivoco a seus seguidores, principalmente percebido nos estudos de Munby (1978).

Ainda na compreensão de Taylor (1988), a competência contextual ou sociolinguística de Canale \& Swain (1980) pode ser facilmente relacionada à noção de Chomsky sobre a competência pragmática. Os autores avançam na discussão, pois propõem que a competência comunicativa seja compreendida na relação e interação entre a competência gramatical e a competência sociolinguística, excluindo, porém, a noção de habilidade para o uso ${ }^{\text {iii }}$. Nesse sentido, Canale \& Swain (op. cit., p. 7) enfatizam que "usaram a noção de competência - seja ela comunicativa, gramatical, ou o que seja - para se referirem ao conhecimento subjacente em uma dada esfera".

Widdowson (1989, p. 128) - pontuando que Taylor (1988) examina o conceito do termo competência com notável percepção - enfatiza que a visão de Chomsky não abrangeu o comportamento da língua de forma premeditada. Porém, não por considerála um detalhe irrelevante (como destacado por Canale \& Swain, 1980), mas sim por se deter tão somente em um tipo de conhecimento que foi reconhecido por Chomsky como "um sistema de regras, de parâmetros ou princípios, configurações na mente para a qual a língua simplesmente serve como evidência".

Widdowson (1989, p. 129) ratifica que "Hymes propôs seu conceito de competência comunicativa em reação a Chomsky", mas que ambos "jogam em 
diferentes tipos de jogo", já que um está interessado no uso da língua e outro não. Aliás, Widdowson salienta que Chomsky não estava nem mesmo interessado na língua, mas sim na gramática da língua, o que desvincula totalmente de sua teoria noções sobre comportamento da língua e conceitos como comunicativo, habilidade - percepções que embasam a teoria de Hymes. Dessa forma, a competência para Chomsky, segundo Widdowson (op. cit., p. 129), "é o conhecimento gramatical enquanto um estado mental profundamente arraigado abaixo do nível da língua", enquanto que para Hymes "é uma habilidade para fazer algo: para usar a língua", sendo o conhecimento gramatical "um recurso, não uma configuração cognitiva abstrata que existe por si só enquanto uma estrutura mental".

Para Widdowson (1989, p. 130; itálico do autor), ainda, o termo competência pragmática em Chomsky se refere de fato a "um tipo de habilidade" em relação direta, porém profundamente separada com a noção do termo competência gramatical que significa "um tipo de conhecimento". Dessa forma, a relação Hymes-Chomsky, como enfatizado acima por Taylor (1988), faz-se evidente nesse contexto, já que o termo habilidade aparece nos argumentos dos dois autores, embora Chomsky não compreendesse, de forma alguma, o termo conhecimento a partir do sentido de "appropriateness" sugerido por Hymes (sentido, depois, incorporado na visão de competência pragmática). Assim, segundo Widdowson, Chomsky havia pensado, inconscientemente - da mesma forma como se constituía um dos pensamentos recorrentes do movimento comunicativo ao romper com o movimento gramatical -, na possibilidade de um falante possuir uma competência gramatical total, porém nenhuma competência pragmática, ou seja, qualquer habilidade para usar a língua de forma apropriada.

\section{6) Competência ecológica e simbólica}

O termo competência ecológica é usado por Kramsch (2006) ao criticar a ênfase na competência comunicativa no ensino comunicativo de línguas, cuja base funcional, conforme a autora, ocupa-se mais com o que a língua "faz" (atos de fala), sua eficiência, do que com que a língua "diz". Para a autora, que usa também o termo competência simbólica, "os aprendizes de língua não são apenas comunicadores e solucionadores de problemas, mas pessoas inteiras com corações, corpos, mentes, memórias, fantasias, lealdades, identidades" (p. 251), e aprender uma língua é muito mais do que "aprender como se comunicar enquanto um membro de um grupo sociocultural particular" (Breen \& Candlin, 1980, p. 90) e do que estar exposto a insumos autênticos e compreensíveis. Do mesmo jeito, formas simbólicas "não são apenas itens de vocabulário ou estratégias de comunicação, mas experiências incorporadas, ressonâncias emocionais e fantasias morais" que se manifestam de várias formas (linguística, textual, visual acústica, poética, etc) (Kramsch, 2006, p. 251).

Assim, a competência simbólica vai além da simples negociação na conversação 
do uso das palavras e seus significados, de "dizer a palavra certa para a pessoa certa no momento certo" ou de se saber como comunicar significados; abordando também a habilidade de "produzir e compartilhar produtos simbólicos no contexto complexo e global em que vivemos hoje", de "compreender a prática de significar, significando" e, dessa forma, "deve ser nutrida pela imaginação literária" (p. 251), já que é por meio da literatura, segundo a autora, que se pode aprender o significado total potencialmente proporcionado pela linguagem. E isso exige dos professores

(...) enxergar a lingua(gem) e a cultura, ou seja, a gramática e o estilo, vocabulário e suas conotações culturais, textos e seus pontos de vista, como inseparáveis. Por outro lado, aprendizes de língua deveriam devagar entender que competência comunicativa não deriva apenas de informações, mas de forças simbólicas que vem com a interpretação dos signos e suas múltiplas relações com outros signos.

A visão de Kramsch está inserida no que van Lier (2000, p. 245) enfatiza como uma perspectiva ecológica no contexto de aquisição de L2, que enfatiza que a educação linguística deva inserir-se numa abordagem ecológica que visa unir "um número de visões bem estabelecidas de ensino de língua, especialmente quando essa abordagem ecológica está ancorada em uma visão de mundo ecológica".

Em termos mais abrangentes, uma abordagem ecológica, ainda segundo van Lier, está fundamentada na crítica de três premissas subjacentes ao pensamento científico clássico (resumidamente apresentadas aqui), quais sejam: (1) para investigar é necessário simplificar, decompor, reduzir; (2) a aprendizagem de língua é um processo mental, cerebral; (2) a atividade social e a interação dialógica (verbal ou não verbal) estão indiretamente relacionadas à aprendizagem, via processo cognitivo. Por outro lado (também resumidamente), a concepção ecológica trata: (1) a investigação em termos de emergências, descartando o reducionismo, a simplificação; (2) a aprendizagem e a cognição como processos que vão além das explicações do que acontece na mente, no cérebro; (3) a atividade social e a interação dialógica não como facilitadores da aprendizagem, mas como sendo elas mesmas aprendizagens.

O termo ecologia, como pontua van Lier (2000, p. 251), "refere-se à totalidade da relação de um organismo com todos os outros organismos que ele tem contato" e, apesar de ser um conceito cunhado por ecologistas nos estudos da biosfera e/ou ecosfera, é também usado para denotar uma visão de mundo ecocêntrica ou geocêntrica que é completamente diferente da visão antropocêntrica do universo reducionista e racional cartesiano que os estudos da lingua(gem) têm se apoiado por muito tempo, implícita ou explicitamente.

\section{Considerações Finais}

Durante muito tempo, e ainda nos dias atuais, discute-se muito qual o conhecimento, a compreensão e/ou a competência que se faz necessário/a para que se 
adquira/desenvolva uma LE/L2 ou para se possa entender a aquisição/desenvolvimento de uma LM. No entanto, como tentei mostrar neste artigo (tópicos de 1 a 5), não há um consenso sobre essa questão, o que necessariamente vêm conduzindo os estudos da lingua(gem) a novas formas de reflexões, menos reducionistas e/ou simplificadoras. A visão ecológica apresentada por Kramsch (2006) e van Lier (2000) - enfatizada no último tópico deste artigo - é apenas uma pequena mostra do direcionamento que especialistas vêm tomando nos estudos da lingua(gem). Dentro desse panorama contemporâneo (situado no paradigma da complexidade), o conhecimento, a compreensão e/ou a competência na aquisição/desenvolvimento de uma LE/L2 ou de uma LM deve ser compreendido/a e/ou investigado/a como um fenômeno complexo, emergente, não linear e com características de imprevisibilidade. Dessa forma, tal fenômeno deve englobar todos os fatores (e ir além deles) previstos nesse processo, como dispostos em Palmer, Chomsky, Piaget, Hymes, Halliday e tanto outros autores citados ou não neste artigo. O que exige da área novas formas complexas de reflexão.

\footnotetext{
${ }^{\mathrm{i}}$ Veja o artigo de Eichler \& Fagundes (2005) que disponibiliza uma evolução atualizada do debate Chomsky-Piaget.

ii Nesse contexto, o termo "situacional refere-se ao uso concreto de objetos, figuras, objetos e atividades educativas, que juntos com ações e gestos podem ser usados para demonstrar os significados dos novos itens da língua" (Richards \& Rodgers, 2004, p. 43). Aqui, ainda, o termo se refere ao que na literatura da área encontra-se como método situacional, que diverge fundamentalmente do termo planejamento situacional (como proposto por Wilkins em 1976). De acordo com Salimbene (1983, p. 3), o método situacional, por um lado, "usa contextos significativos para apresentar estruturas gramaticais" - já que esse método faz parte de um planejamento gramatical com uma metodologia baseadas no desenvolvimento de hábitos -; o planejamento situacional, por outro lado, "considera a língua num contexto social e 'é baseado em predições da situação em que o aprendiz é provável de operar através da língua estrangeira $"$ " - contexto identificado através da analise de necessidade.

iii Taylor (1988, p. 158; tradução nossa) enfatiza, todavia, que "infelizmente, mas tipicamente nesse campo, Canale, num artigo posterior que seria um refinamento desse, comete um deslize quando ele explicitamente associa a competência gramatical com 'habilidade' (Canale, 1983: 7)”.
}

\section{Referências Bibliográficas}

ALLEN, J. P. B. \& WIDDOWSON, H. G. "Grammar and language teaching". In: ALLEN, J. P. B. \& CORDER, S. P. Papers in applied linguistics. The Edinburgh course in applied linguistics. Vol. 2, London: Oxford Univesity Press, 1975, pp. 45-97.

BACHMAN, L. "Communicative language ability". In: Language Testing. New York: Oxford Press, 1990. pp. 80-110.

BREEN, H. \& CANDLIN, C. "The essentials of a communicative curriculum in language teaching". Applied Linguistics, vol. 1, 1980, pp. 89-112.

CAMPBELL, R. \& WALES, R. "The study of language acquisition". In: LYONS, J. 
(org.) New horizons in Linguistics. Harmonds-worth, Middx: Penguin Books, 1972.

CANALE, M. "From communicative competence to communicative language pedagogy". In: RICHARDS, J. C. \& SCHMIDT, R. W. (eds.) Language and Communication. New York: Longman, 1983.

CANALE, M. \& SWAIN, M. "Theoretical bases of communicative approaches to second language teaching and testing”. Applied Linguistics, vol. I(1), 1980, pp. 1-47.

CELCE-MURCIA, M. "Rethinking the role of communicative competence in language teaching”. In: SOLER, E. A. \& JORDÁ, M. P. S. (eds.). Intercultural Language Use and Language Learning. Dordrecht: Spring, 2007, pp. 41-57.

CELCE-MURCIA, M., DÖRNYEI, Z. \& THURREL, S. "Communicative competence: a pedagogically motivated model with content specifications". Applied Linguistics, vol. 6, 1990, pp. 5-35.

CHOMSKY, N. Rules and representation. Oxford: Temple Smith, 1980.

. "A propósito das estruturas cognitivas e de seu desenvolvimento: uma resposta a Piaget". In: Teorias da linguagem. Teorias da aprendizagem: o debate entre Jean Piaget \& Noam Chomsky. Tradução de Álvaro Cabral. São Paulo: Cultrix: Ed. da USP, [1978] 1983.

Aspects of the theory of syntax. Cambridge, MA: MIT Press, 1965.

CRIPER, C. \& WIDDOWSON, H. G. "Sociolinguistics and language teaching". In: ALLEN, J. P. B. \& CORDER, S. P. Papers in applied linguistics. The Edinburgh course in applied linguistics. Vol. 2, London: Oxford Univesity Press, 1975, pp. 155217.

EICHER, M. L. \& FAGUNDES, L. "Atualizando o debate entre Piaget e Chomsky em uma perspective neurobiological”. Psicologia: Reflexão e Crítica, vol. 18(2), 2005, pp. 255-66.

FASOLD, R. The sociolinguistics of language. Cambridge: Backwell, 1990.

GREENE, J. Psycholinguistics. Harmondsworth: Penguin, 1972.

HALLIDAY, M. A. K. Language and social semiotic. London: Edward Arnold, 1978.

HOWATT, A. P. R. \& WIDDOWSON, H. G. A history of English language teaching. $2^{\text {nd }}$ ed. Oxford: Oxford University Press, 2004.

HYMES, D. “On communicative competence”. In: PRIDE, J. B. \& HYMES, J. (eds.) Sociolinguistics: selected readings. Harmondsworth, England: Penguin, 1972.

. "Competence and performance in linguistic theory". In: HUXLEY, R. \& 
INGRAN, E. (eds.) Language acquisition: models and methods. New York: Academic Press, 1971.

KRAMSCH, C. "From communicative competence to symbolic competence". The modern Language Journal, v. 90, 2006, pp. 249-252.

LEMIEUX, C. P. "Harold E. Palmer's contribution to the Oral Method of Teaching Foreign Languages". The Slavic and East European Journal, vol.8(3), 1964, p. 320-6.

LYON, J. As ideas de Chomsky. São Paulo: Cultrix, 1973.

MATTHEWS, P. H. "Language as a mental faculty: Chomsky's progress". In: COLlingE, N. E. (ed.) An encyclopaedia of language. London: Routledge, 1990.

MUNBY, J. Communicative syllabus design: a sociolinguistic model for defining the content of purpose-specific language programmes. Cambridge: Cambridge University Press, 1978.

PALMER, H. E. The oral method of teaching language. A monograph on conversational methods together with a full description and abundant examples of fifty appropriate forms of work. $2^{a}$. ed., Cambridge: W. Heffer \& Sons Ltd., 1922.

. The principles of language study. Londres, [1921] 1964.

. The scientific study and teaching of languages. Londres, [1917] 1968.

PAULSTON, C. B. "Linguistic and communicative competence". TESOL Quarterly. Vol. 8(4), 1974, pp. 347-62.

PIAGET, J. "Psicogênese dos conhecimentos e seu significado epistemológico". In: Teorias da linguagem. Teorias da aprendizagem: o debate entre Jean Piaget \& Noam Chomsky. Trad. de Álvaro Cabral. São Paulo: Cultrix: Ed. da USP, [1978] 1983.

PIATTELli-PALMARINI, M. (org.) Teorias da linguagem. Teorias da aprendizagem: o debate entre Jean Piaget \& Noam Chomsky. Trad. de Álvaro Cabral. São Paulo: Cultrix: Ed. da USP, [1978] 1983.

RICHARDS, J. C. \& RODGERS, T. Approaches and methods in language teaching. 2a. ed., Cambridge: Cambridge University Press, 2004.

SALIMBENE, S. "From structurally based to functionally based approaches to language teaching". English Teaching FORUM, vol. XXI(1), 1983, pp. 2-7.

SAUSSURE, R. Curso de linguistic geral. 4a. ed.. São Paulo: Cultrix, [1916] 1972.

TAYLOR, D. S. "The meaning and use of the term 'competence' in Linguistics and Applied Linguistics". Applied Linguistics, vol. 9(2), 1988, pp. 148-68. 
VAN LIER, L. "From input to affordance: social-interactive learning from an ecological perspective". In: LANTOLF, J. P. Sociocultural theory and second language learning. Oxford: Oxford University Press, 2000, pp. 245-257.

WIDDOWSON, H. G. "Knowledge of learning and ability for use". Applied Linguistics, vol. 10, 1989, pp. 128-37.

WIEMANN, J. M. \& BACKLUND, P. "Current theory and research in communicative competence”. Review of Educational Research, 50(1), 1980, pp. 185-99. 